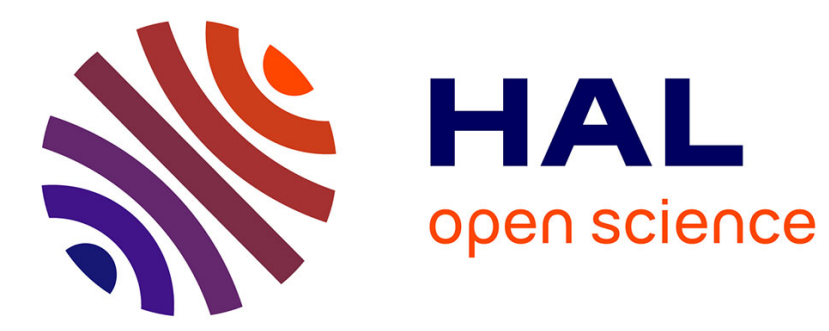

\title{
Submicron Desert Dusts: A Sandblasting Process
}

Laurent Gomes, Gilles Bergametti, Genevieve Coudé-Gaussen, Pierre Rognon

\section{To cite this version:}

Laurent Gomes, Gilles Bergametti, Genevieve Coudé-Gaussen, Pierre Rognon. Submicron Desert Dusts: A Sandblasting Process. Journal of Geophysical Research, 1990, 95 (D9), pp.927-940. hal02326426

\section{HAL Id: hal-02326426 \\ https://hal.science/hal-02326426}

Submitted on 22 Oct 2019

HAL is a multi-disciplinary open access archive for the deposit and dissemination of scientific research documents, whether they are published or not. The documents may come from teaching and research institutions in France or abroad, or from public or private research centers.
L'archive ouverte pluridisciplinaire HAL, est destinée au dépôt et à la diffusion de documents scientifiques de niveau recherche, publiés ou non, émanant des établissements d'enseignement et de recherche français ou étrangers, des laboratoires publics ou privés. 


\title{
Submicron Desert Dusts: A Sandblasting Process
}

\author{
LAURENT GOMES AND GILLES BERGAMETTI
}

\author{
Laboratoire de Physico-Chimie de l'Atmosphère, Université Paris VII, Paris
}

\section{GENEVIEVE COUDÉ-GAUSSEN AND PIERRE ROGNON}

\author{
Laboratoire des Paléoenvironnements et Paléoclimats en Milieu Aride, \\ Université Pierre et Marie Curie, Paris
}

\begin{abstract}
Mass size distributions of the major elements of the mineral aerosol of northem Sahara were obtained from measurements carried out with an inertial cascade impactor. A fitting procedure by data inversion was applied to these data. This technique considers the major mechanisms of nonideal behavior such as particle bounce-off, wall losses and cross sensitivity which affect the accuracy of impactor measurements of aerosol size distribution. Accurate size distributions of Saharan aerosol (range 0.1-20 $\mu \mathrm{m}$ ) were so obtained for different conditions of soil mobilization. These measurements, coupled with wind speed information, show the shape of the size distribution for desert aerosols in the considered range to be characterized by a similar pattern with a common mode of particles having diameter between 1 and $20 \mu \mathrm{m}$ whatever the weather conditions. A second mass peak of submicron particles appears when the wind speed increases above the threshold value for erosion. Scanning electron microscope photographs indicate that the whole granulometric spectrum of the sampled aerosol between 0.1 and $20 \mu \mathrm{m}$ mainly consists of clay easily disaggregated by sandblasting. The common origin of submicron particles with those between 1 and $20 \mu \mathrm{m}$ is established by showing the similar composition of dusts in the both modes. The results suggest that the presence of submicron mineral particles during dusty and sandstorm conditions is consistent with a sandblasting process.
\end{abstract}

\section{INTRODUCTION}

It has been shown that the dusts emitted from the arid areas of the Earth, and especially from the Sahara Desert, are a significant source of tropospheric aerosol particles [Junge, 1979; Schütz, 1980]. These mineral particles may be able to induce climatic effects by acting on cloud physics and on the global radiative budget of the Earth [Carlson and Caverly, 1977; Carlson and Benjamin, 1980].

Their atmospheric impact is strongly dependent on their size distribution. It is clear that fine particles, which can remain airborne for long periods, can be transported over long distances [Pye, 1987]. Moreover, the extinction coefficient of atmospheric particles is generally related by the Mie theory to the size distribution and optical properties of this atmospheric particulate matter. The optically important atmospheric aerosols, as well as the long-range transported soil fraction, are generally considered within the $\mathrm{d}$ (equivalent diameter) $<10 \mu \mathrm{m}$ size range.

A model capable of simulating the mobilization of soil material [Westphal et al., 1987] shows that the original soil size distribution is modified during mobilization by sizedependent lifting mechanisms and by mixing with other aerosol components. Hence, it is necessary to assess the size distribution of the soil-derived aerosols over the source region for various deflation conditions. Very few data on this subject are available.

For the great American deserts, the size distributions of

Copyright 1990 by the American Geophysical Union.

Paper number $90 \mathrm{JD} 00110$.

0148-0227/90/90JD-00110\$05.00 soil-derived aerosols were mainly investigated within the size range $1.2<\mathrm{d}<200 \mu \mathrm{m}$ [Chepil, 1957; Chepil and Woodruff, 1957; Patterson et al., 1976; Gillette and Walker, 1977; Gillette et al., 1978]. The mass contained by crustal generated particles finer than $1 \mu \mathrm{m}$ was generally considered as practically negligible. This is due to either the inability of the measurement methods to detect the particles smaller than $0.5 \mu \mathrm{m}$ or because the contribution to submicron particles is largely attributed to sources other than soil. In summary, previous studies have shown that the size distribution of particles collected at 1-2 $\mathrm{m}$ above ground exhibits two size modes, one between 2 and $20 \mu \mathrm{m}$ and another between 20 and $200 \mu \mathrm{m}$. It has been demonstrated that the particles of the smallest size mode are derived from the exposed soils by sandblasting processes, as described by Gillette and Walker [1977], during wind erosion.

An earlier study by Schütz and Jaenicke [1974] in the central Sahara Desert was performed during various atmospheric conditions in order to measure the particle size distribution of soil and associated aerosol. Although this preliminary attempt was restricted to particles with $d>2$ $\mu \mathrm{m}$, the importance of fine particles fraction in the production of soil wind erosion aerosols and in the process of long range transport of dust was highlighted. D'Almeida and Schütz [1983] completed the study of the size distribution of mineral particles in the submicron range for some soils and aerosols of the middle and southern Sahara. The number size distribution of mineral aerosol showed a maximum below $0.1 \mu \mathrm{m}$ radius and the volume distribution of mineral aerosol a well-developed bimodal structure with maxima at 3 and $30 \mu \mathrm{m}$ radius respectively. 
It is now clearly evident from the previous works, that the maximum of the mineral aerosol number distribution is located below $1 \mu \mathrm{m}$ over the source region, while the volume or mass distribution enhances two modes respectively located within the $2-20 \mu \mathrm{m}$ and $20-200 \mu \mathrm{m}$ size ranges.

The purpose of this work is to document the particle size distributions of desert dusts smaller than $20 \mu \mathrm{m}$ over the source region, during dusty and normal conditions. Chemical compositional studies were conducted to assess precisely the actual desert origin of dusts. The mass distribution of some elements which originate exclusively from crustal sources in desert areas were measured with an inertial cascade impactor. Then, since nonideal effects limit the impactor performance resulting in erroneous and misleading size distribution data, a fitting procedure was used to describe the obtained mass size distributions. Here, we present the procedures and methods used, results and a discussion of the data as obtained under different sampling conditions in the northern Sahara Desert.

\section{DATA ACQUISITION}

\section{Sampling}

The sampled aerosols originate in the northem Sahara Desert. In this part of the Saharan Desert, the frequency of dust winds is maximal during spring and minimal in winter [Dubief, 1952]. Therefore, a series of measurements were carried out in order to collect a data set during different seasonal field periods (April, 1986 and December, 1987) from a site located on the southern margin of the Saharan Atlas in Algeria (El Abiod Sidi Cheikh, 32'54' N, 0'33' E, see Figure 1). This location is typical of the northern Sahara. First, the absence of industrial activity and the limited vehicular traffic in this area restrict the possible sources of local pollution. Secondly, this site $(900 \mathrm{~m}$ in altitude) is characterized by a subarid climate (annual rainfall $<117 \mathrm{~mm}$ ) and by a scattered vegetation. The prevailing winds come from the northwest, passing through the Atlas mountains at around $1000-1500 \mathrm{~m}$ in altitude. These mountains are formed with sandstone rocks and produce large amounts of sand which are carried out by winds toward the western Sandsea, up to $200 \mathrm{~km}$. On the other hand, El Abiod is located in the floodplain of a large wadi which leaves its silt and clay load, upstream from a vast piedmont. Consequently, wind erosion often spreads into clay soil plains by the incursion of sandblasting sand from an upwind source.

The horizontal wind speed was recorded on this site, at $6 \mathrm{~m}$ above the ground, during both periods of measurements. In April, moderate to strong northwesterly winds can usually be related to depressions involving the Sahara. These winds increase in intensity during the morning, reaching a maximum during the afternoon. Their turbulence is therefore mainly of thermic origin. Dust particles are thus violently raised from the ground usually
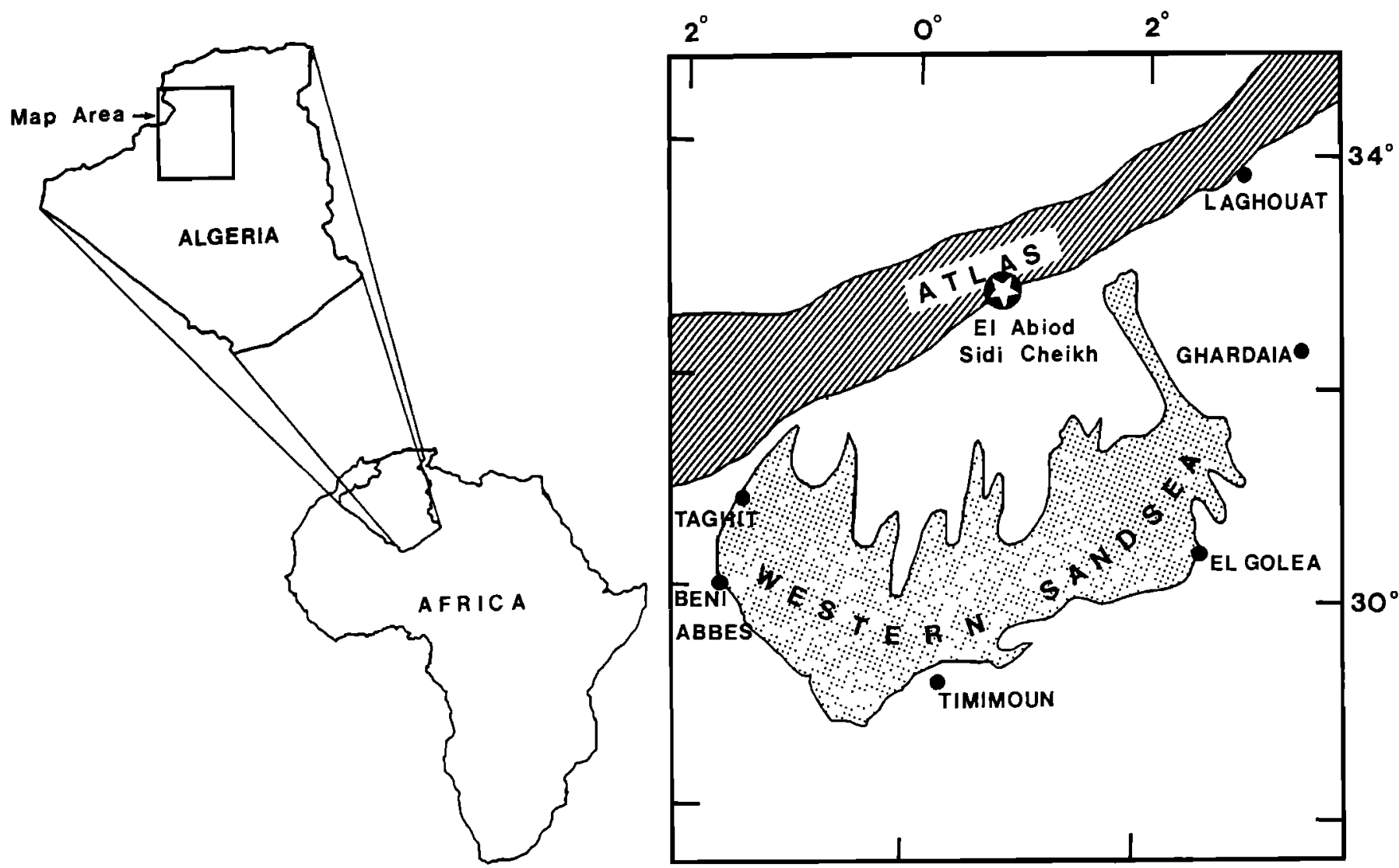

Fig. 1. Location of the sampling site. 
in the form of dust storms as a result of strong surface wind. Nevertheless, a previous study conducted in the western Sahara [Helgren and Prospero, 1987] showed that the dust-raising events are generally associated with a threshold wind velocity which varies with the environmental characteristics of the terrain.

Dust particles were collected at a 6-m height, during times ranging from 6 hours to 24 hours, with a model EGAI 80 low volume cascade impactor [Bergametti et al., 1982] which was operated at the nominal flow rate of $1 \mathrm{~m}^{3} \mathrm{~h}-1$. This impactor is a single-jet sampler with five stages and a final backup filter. For this airflow, the size cutoff diameters $\left(D_{s_{0}}\right)$ are about 8.75, 3.9, 1.95, 1.25 and $0.65 \mu \mathrm{m}$ for stages 1 to 5 respectively. The final backup filter has a reported collection efficiency of more than $90 \%$ for $0.1 \mu \mathrm{m}$ diameter particles. Nuclepore $0.4-\mu \mathrm{m}$ pore size filters were used as particle impaction surfaces on the five impactor stages and for the final backup filter. Impactor characteristics including impactor response functions and nonideal effects such as particle bounce or wall losses were discussed in detail in a previous study [Gomes et al., 1990].

This latter study shows that the use of an EGAI 80 cascade impactor minimizes the wall losses. On the other hand, the cross sensitivity and bounce-off effects have to be taken into account in the data processing. Indeed, in the case of aerosols of dominantly crustal origin (as aluminosilicates), bouncing occurs due to the inability of dry solid particles to adhere to dry impaction surfaces. However, usual methods to minimize it, as the application of an adhesive agent to the impaction surfaces or the use of glass or cellulose filters, cannot be applied because the analytical procedures subsequently used require smooth flat surfaces and low blank values for trace element analyses.

\section{Analytical Method}

Chemical analyses were performed by wavelength dispersive $\mathbf{X}$ ray fluorescence spectrometry (CGR alpha 10) according to the method described by Losno et al. [1987], using an $\mathrm{X}$ ray tube with $\mathrm{Cr}$ or $\mathrm{W}$ targets. The collected samples were directly used in the spectrometer without any further preparation. Each sample was counted two times using a proportional gaseous flux detector and the K-alpha ray of key elements such as $\mathrm{Al}, \mathrm{Si}, \mathrm{P}, \mathrm{K}, \mathrm{Ca}, \mathrm{Ti}, \mathrm{Mn}$ and $\mathrm{Fe}$. Total counts are corrected for blank filter counts; analytical precision is better than $7 \%$ for every element analyzed. The gold plated samples were examined by a Jeol JSM 2 scanning electron microscope (SEM) fitted with an energy dispersive $X$ ray analyzer (EDS Ortec) for characterization of grain shape, surface features and particle mineralogy.

\section{Data Processing}

Since the tropospheric particle size distributions are usually reported as multimodal distribution functions, the mass-size distributions were obtained by using the data processing procedure described by Gomes et al. [1990]. This study proposes an improvement of the data inversion technique by Puttock [1981] for fitting multimodal distributions by particle mass with lognormal components, and correcting these experimental mass-particle size distributions for the particle bouncing effect. The use of lognormal modes for fitting particle size data has been extensively justified by various workers [Blifford and Gillette, 1971; Davies, 1974; Jaenicke and Davies, 1976; Patterson and Gillette, 1977; Jaenicke, 1985; Kim et al., 1988; Gomes et al., 1990]. The mathematical properties of the lognormal law imply that the aerosol size distribution is due to multiplicative effects as comminution processes (e.g., sandblasting). The bounce-off contribution to smaller size stages could be estimated by the difference between the experimental and fitted mass size distributions. Therefore, the fitting procedure used allows the determination of mass-particle size distribution parameters, corrected for the usual errors due to bouncing. After correction, one can assume that the bounce-off effect generates uncertainties in a range comparable to the analytical errors ( $<7 \%$ of the total concentration sampled).

\section{RESULTS}

As expected, weather conditions and particularly changes of wind stress were quite different between the field samplings. During the spring period of 1986, four samples were taken, while the mean wind velocity ranged from 5 to $9 \mathrm{~m} \mathrm{~s}^{-1}$. This period was characterized by a heavy aerosol loading in the atmosphere due to frequent dust storms, with reduced visibility and a high production of soil aerosols.

In contrast, the winter period of 1987 , during which five other samples were taken, was characterized by steady calm weather with wind velocities of $<4 \mathrm{~m} \mathrm{~s}^{-1}$ and a light aerosol loading, with no erosion at the time of the sampling.

Concentrations of $\mathrm{Si}$, which is the major element in the composition of desert soil, were used to distinguish cases of high aerosol loading in the atmosphere resulting from an increase of wind speed over the threshold for erosion from cases with less aerosol loading or light aerosol loading with little or no local deflation. The whole measurements provided by both the campaigns allow us to draw the general relationship, shown in Figure 2, between the $\mathbf{S i}$ mass concentration and the wind speed. From this figure, we note that the atmospheric aerosol loading is strongly dependent on the wind stress. However, another important feature is that seasonal measurements differ from each other primarily because of the level of aerosol loading in the atmosphere.

A strong correlation often exists between particle concentration and horizontal wind speed [Gillette and Porch, 1978; Jaenicke, 1985]. This correlation is generally interpreted as an indication of the sandblasting effect of saltation, which increases greatly with increasing wind speed [Gillette and Porch, 1978]. Nevertheless, in recent years there has been concern expressed by many authors (the earlier one being Dubief [1952]) that the dust rise is better related to the wind turbulence, as reflected in a large 


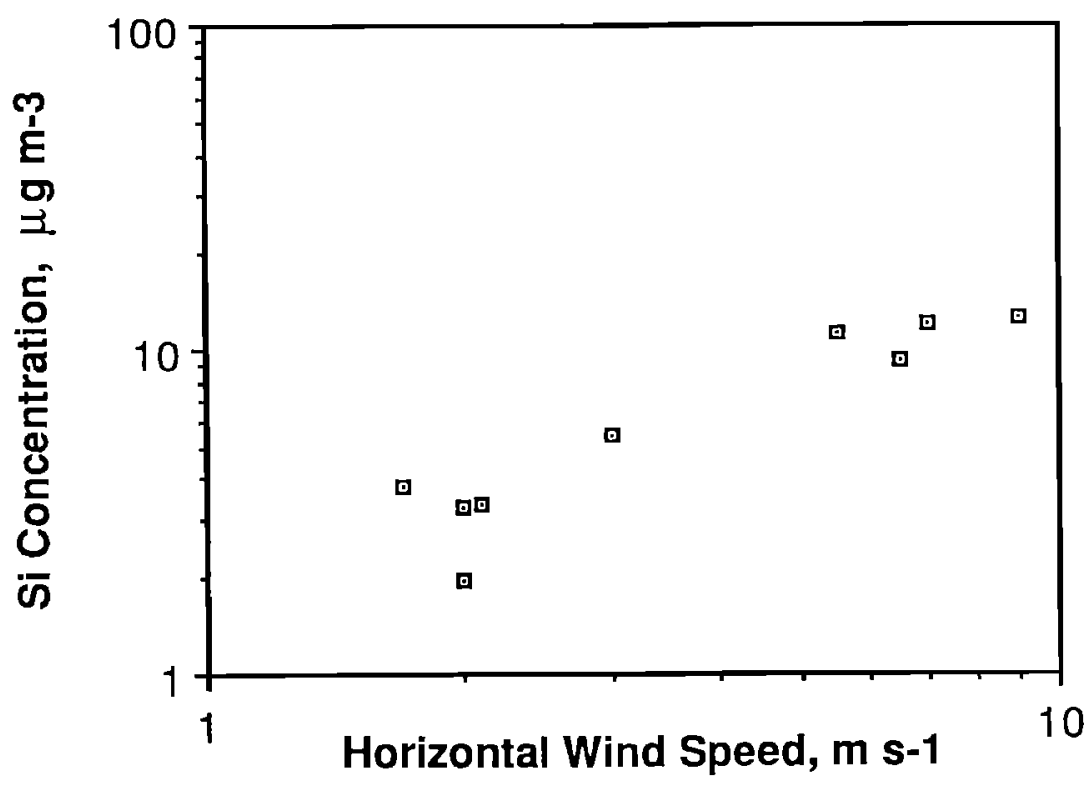

Fig. 2. Silicon mass concentration as a function of horizontal wind speed in El Abiod (northern Sahara).

unsteadiness of the wind speed, particularly in its vertical component. Unfortunately, the vertical wind speed was not measured in our experiment.

In the same way, the erosion threshold friction velocity appears to be an essential parameter to measure in studying the soil particle input into the atmosphere [Gillette, 1974]. However, this parameter, which is relative to the soil characteristics and the aerodynamic properties of the surface [Gillette et al., 1980, 1982], was difficult to estimate in the present study because the state of the soil structure was not carefully determined.

Therefore, in order to examine the variation of the aerosol size distribution as a function of the wind strength, it was more practical to characterize this size distribution according to the dust particle concentration in the atmosphere rather than to attempt to find a relationship between the aerosol size distribution and the horizontal wind velocity. In other words, it was assumed that atmospheric dust loading represented the best indicator of the eroding wind strength. Consequently, only two cases were considered, depending on whether the wind strength was above or below the threshold value for dust mobilization.

Figures 3 and 4 show the general form of the measured mass size distribution of $\mathrm{Si}, \mathrm{Al}$ and $\mathrm{Ca}$ over the size range 0.1 to $20 \mu \mathrm{m}$ for measurements characteristic of the aerosol sampled during both periods. The dashed lines represent the observed mass size distributions, in terms of relative stage loading per unit of $\log$ diameter scale. These distributions are normalized so that the integral of the histogram in a given size range represents the percentage of mass in this size range. The aerosol distributions, whose parameters are provided by the data inversion procedure, are shown by the solid lines. In summary, the dashed lines depict the experimental partitioning of the distributions through the different stages of the impactor. The distortions generated by the impactor response functions can be large, and the fitting procedure applied to cascade impactors is essential in resolving atmospheric size distributions, particularly those complex ones with several populations. This procedure allows the accurate determination of the mean diameter for each mode whose magnitude and width are respectively expressed in terms of the amplitude and the standard deviation of the lognormal distribution. Figure 3 represents a typical case of light aerosol loading (background, $\mathrm{Si}=1.9 \mu \mathrm{g} \mathrm{m}^{-3}$, wind speed $=2 \mathrm{~m} \mathrm{~s}-1$ ) while Figure 4 shows a typical case of heavy aerosol loading ( $\mathrm{Si}$ $=12.5 \mu \mathrm{g} \mathrm{m}^{-3}$, wind speed $\left.=9 \mathrm{~m} \mathrm{~s}^{-1}\right)$. All the size distributions measured during the dusty season were similar to that presented in Figure 4, while the winter measurements look like that shown in Figure 3.

Measurements of the size distribution for desert aerosols have shown that this aerosol size distribution is multimodal in the range 2-200 $\mu \mathrm{m}$ [Patterson and Gillette, 1977; d'Almeida and Schütz, 1983] although the desert aerosol is a purely single-source natural aerosol in which soil-derived particles are predominant. Gillette and Walker [1977] have shown that the different modes can be attributed to different mineral components (mainly quartz, between 20 and $200 \mu \mathrm{m}$, and clay minerals, between 2 and $20 \mu \mathrm{m})$ and that this multimodal structure is the result of physical processes. In our measurements, the shape of the size distribution for desert aerosols in the range 0.1-20 $\mu \mathrm{m}$ is characterized by a generally similar pattern with a common mode of particles having diameters between 1 and $20 \mu \mathrm{m}$. However, a second mass peak of submicron particles appears when dust concentration (i.e., the wind strength) increases above the threshold of erosion.

\section{DISCUSSION}

\section{Common Mode}

It is evident that, whatever the wind force, a common mode is present centered around $3 \mu \mathrm{m}$ diameter. Moreover, 
BRCGEONO
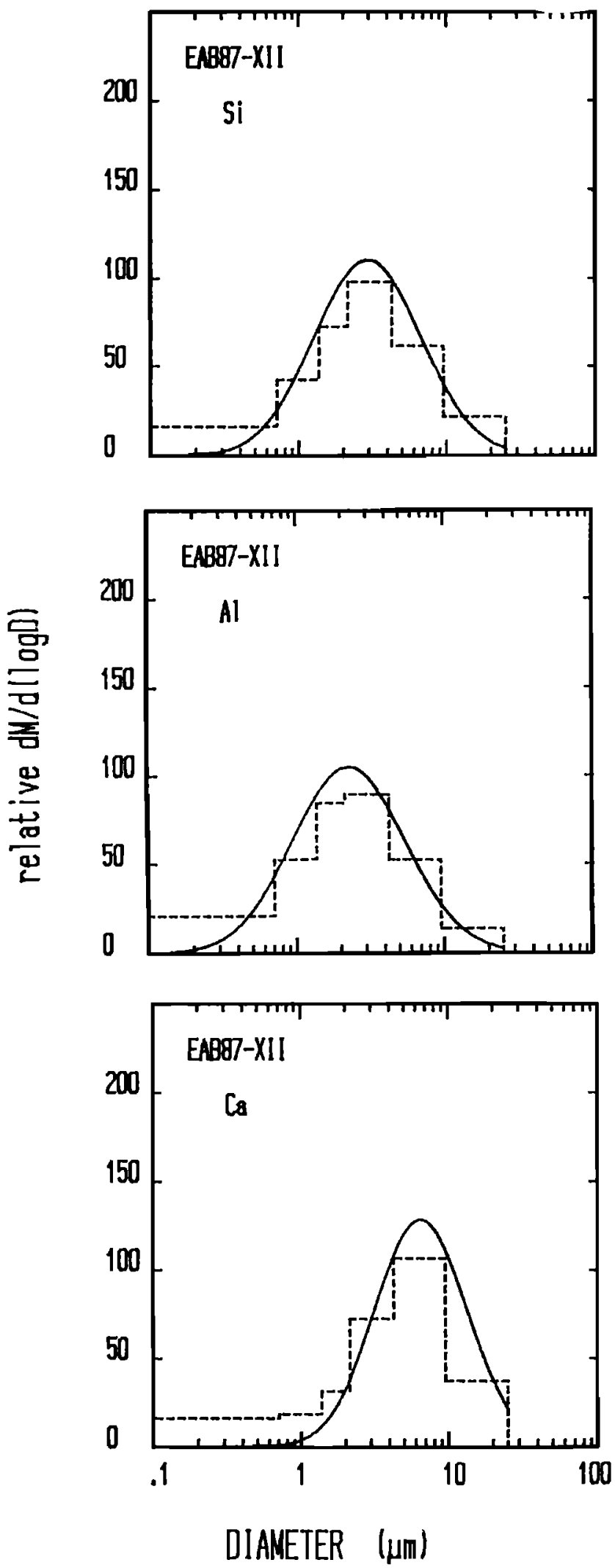

Fig. 3. Typical mass size distribution of $\mathrm{Al}, \mathrm{Si}$ and $\mathrm{Ca}$ for aerosols $<20 \mu \mathrm{m}$ collected by a cascade impactor in northem Sahara (El Abiod) under conditions of light aerosol loading. The dashed line represents the measured stage loadings and the solid line is the lognormal fit to a monomodal distribution. See text for details.
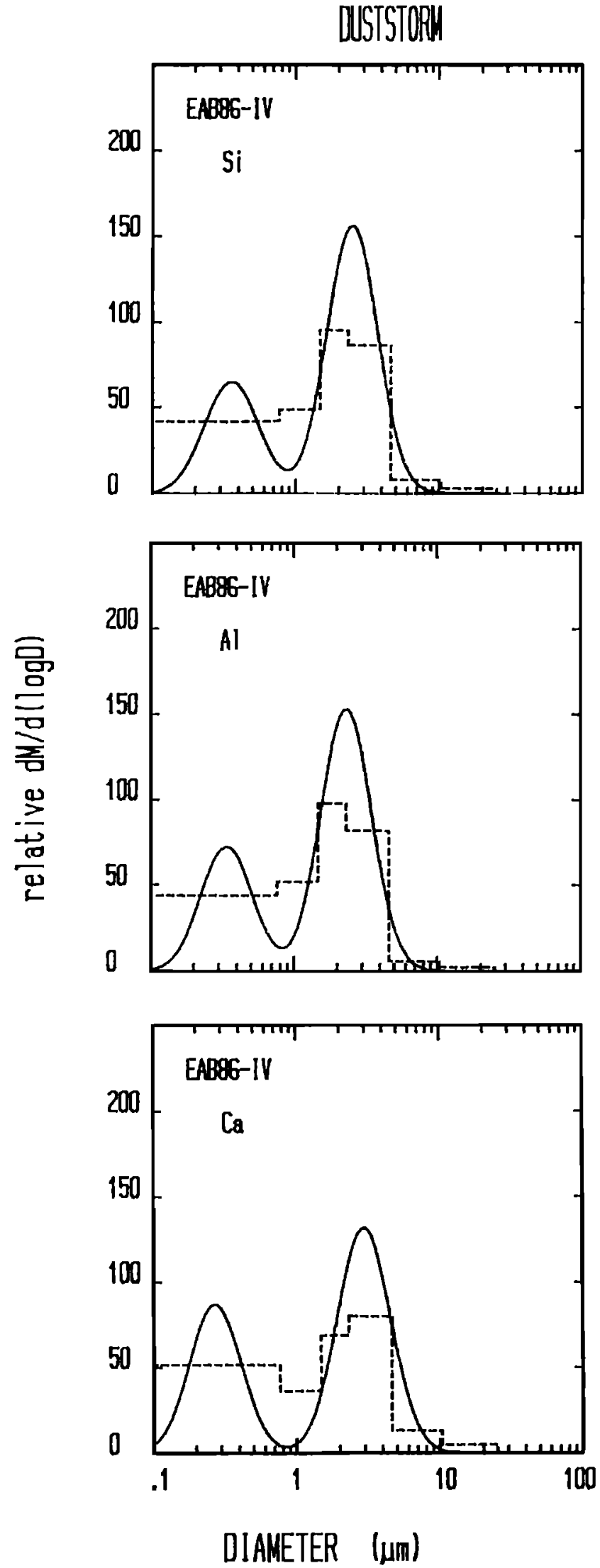

Fig. 4. Typical mass size distribution of $\mathrm{Al}, \mathrm{Si}$ and $\mathrm{Ca}$ for aerosols $<20 \mu \mathrm{m}$ collected by cascade impactor in Northern Sahara (EI Abiod) under conditions of heavy aerosol loading. The dashed line represents the measured stage loadings and the solid line is the lognormal fit to a bimodal distribution. See text for details. 
the size distributions of the aerosols in this mode are similar in shape for every element considered. This singularity corresponds to a sampled material which consists of several major mineral populations (mainly quartz, calcite and clay minerals), all having the same particle size (Figure 5a). Only Ca particles seem larger. We note that all grains are covered by a coating of submicron particles. Moreover, scanning electron micrographs show that the clay minerals appear in the form of platelets (Figure $5 \mathrm{~b}$ ) which are fragile and should be easily comminuted by sandblasting. According to Gillette and Walker [1977], clay is generally removed from the soil as individual platelets, as coating of platelets on quartz grains or as aggregates of platelets. These authors consider that a sandblasting process removes the clay platelets from the surfaces of quartz grains and separates the aggregates.

The presence of such a particle mode is therefore mainly explained by the disaggregation of particles larger than $20 \mu \mathrm{m}$ during the process of sandblasting when the wind velocity is greater than the threshold for erosion. These larger particles (generally around $60 \mu \mathrm{m}$ ), which cannot be aspirated by our impactor, constitute a mode which is characteristic of loose soil aggregates, and therefore represents the local contribution activated during dusty conditions. These particles quickly settle out, while the small settling velocity of particles smaller than $20 \mu \mathrm{m}$ allows them to be carried for longer distances, and to remain airborne for longer periods in the atmosphere. Usually, no injection of particles occurs when wind speed is below the threshold value for erosion, but local concentrations may have been produced by higher wind velocities some days upwind [Jaenicke, 1985]. This explains why this mode is generally observed, even under normal atmospheric conditions [Patterson and Gillette, 1977; d'Almeida and Schütz, 1983].

\section{Submicron Mode}

If it is natural to observe a monomodal distribution centered on $3 \mu \mathrm{m}$ diameter in the size range 0.1 to $20 \mu \mathrm{m}$ under any conditions, then, the bimodal form of the distribution, which is readily apparent when the wind stress increases (Figure 4), is more surprising. However, in their paper relating the results of the ECLATS (Etude de la Couche Limite Atmosphérique Tropicale Sèche) field experiment in the vicinity of Niamey (Niger), Fouquart et

Fig. 5. Scaming electron micrographs of aerosol particles included in the 1-20 $\mu \mathrm{m}$ common mode, collected by filtration during a dust storm at El Abiod (Northem Sahara) are shown in panels a and b. (a) Smoothed quartz grain (Q) with residual crystalline planes; on the right, calcite rhomboedron (Ca); clayey particle (Al, Si, Ca, Fe). All the grains are covered by submicron adhering particles. (b) Clay mineral platelet ( $\mathrm{Al}, \mathrm{Si}, \mathrm{K}, \mathrm{Fe}$ ) with lamelar microstructure. (c) SEM and EDXA analysis of submicron clayey particles collected on the final filter of the cascade impactor during dust storm at $\mathrm{El}$ Abiod: $\mathrm{Al}, \mathrm{Si}$ (particles 2, 7, 11, 19, 20, 21, 23); $\mathrm{Ca}$ (particles 9, 12, 13); Al, Si, Ca (particles 6, 8, 10); Al, Si, K (particles 3, 5); Mg, Al, Si (particles 14, 17, 18); $\mathrm{Mg}, \mathrm{Al}, \mathrm{Si}, \mathrm{K}$ (particle 4).

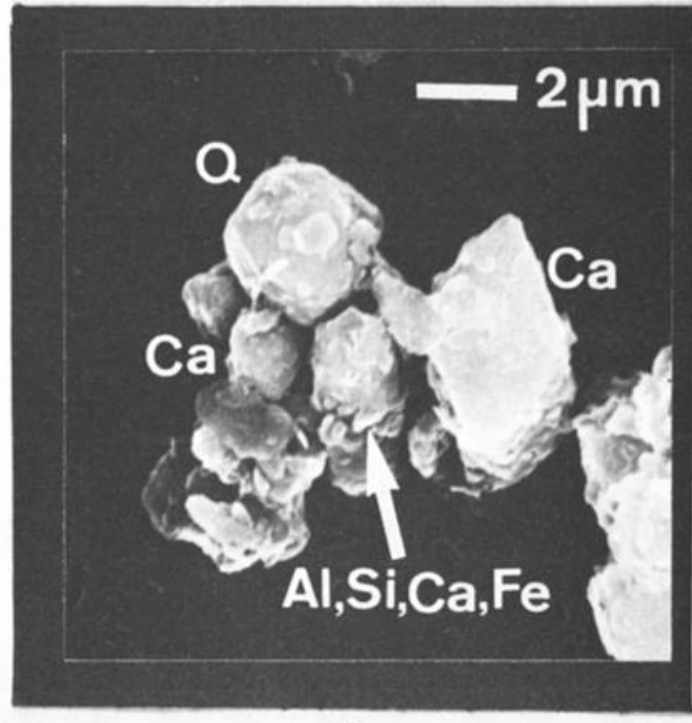

a
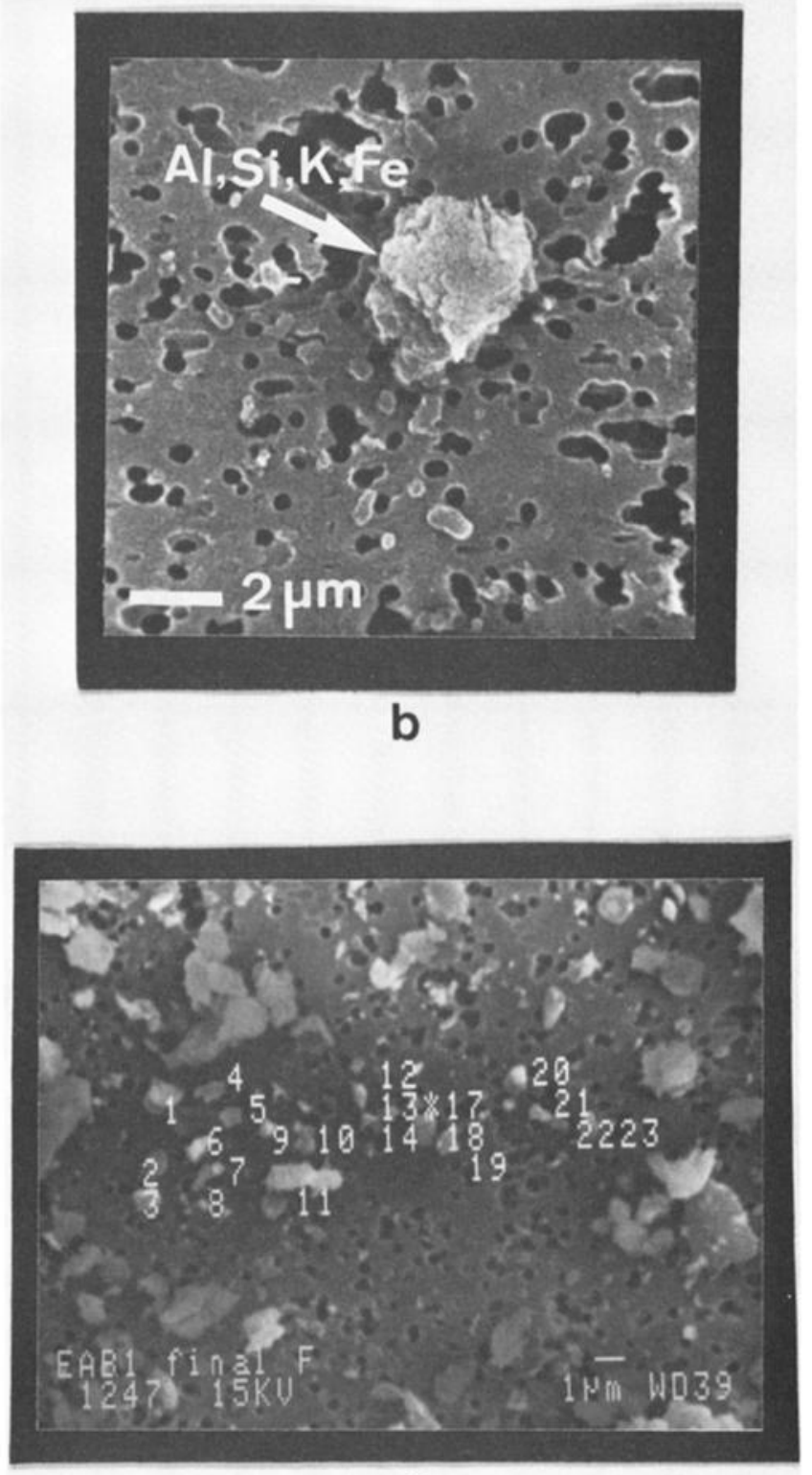

C 
al. [1987] showed that the occurrence of a "dry haze" episode was characterized by a large relative increase of the submicron particles, while the concentration in particles $>2$ $\mu \mathrm{m}$ remained roughly constant. Similarly, in a report on the size distributions of desert aerosol observed in arid regions of Senegal, Mali, and Niger under different weather conditions, d'Almeida [1987] hypothesized that the transition from a sandstorm distribution to a background distribution was characterized by the removal of large particles through sedimentation. It was also observed that the concentrations of submicron particles decreased by a factor of 8 while the concentration of particles around 3 $\mu \mathrm{m}$ remained roughly constant.

Airborne particles collected during a dust storm on the backup filter of our impactor, and which form this submicron mode, are shown in Figure 5c. They appear mainly in the form of fine clayey particles. Some Ca carbonate grains were also observed. No quartz particles were found.

In their compilation of size and volume distributions of soil-derived aerosols over the southwestern American deserts, Patterson and Gillette [1977] attribute the mode consisting of particles with $\mathrm{d}<2 \mu \mathrm{m}$ to anthropogenic secondary aerosols that make up a natural background aerosol. These authors show the existence of such a mode only in the case of low aerosol loading under conditions in which there was little or no local erosion. In our measurements we attribute to windblown dust this second submicron particle mode since it appears when the wind speed increases above the threshold value for erosion. Moreover, this mode is observed for elements resulting principally from soil dust mobilization ( $\mathrm{Al}, \mathrm{Si}, \mathrm{Ca}, \mathrm{Fe}, \mathrm{K}, \mathrm{P}$, $\mathrm{Mn})$. Consequently, the hypothesis of anthropogenic contribution for this submicron component can be ruled out.

Only a few workers have observed a submicron component in soil-derived aerosols. Kondratyev et al. [1974], reporting the results of the Complex Atmospheric Energetics Experiment (CAENEX), indicated the presence of a submicron component of soil-derived aerosols collected in the USSR by means of filters $2 \mathrm{~m}$ above ground surface. This mode appears to consist of small ferric oxide particles sugges. "ye of a different origin from that of the larger particles.

More recently, d'Almeida and Schütz [1983] demonstrated that a mode of crustal-generated particles could also be found in the Aitken particle size range ( $d<$ $0.2 \mu \mathrm{m}$ ). These authors suggested that the Aitken size mineral particles as well as those with $\mathrm{d}<10 \mu \mathrm{m}$ would be the result of the sandblasting process when the larger particles consist of loose aggregates of parent soil. Hence, this classical process might be responsible for the formation and the injection of such particles in the atmosphere. However, this hypothesis is not readily supported because no further investigations on the chemical composition of these submicron particles were made by these authors.

Our data suggest a sandblasting origin for the submicron size component of the desert dusts over the source region. Table 1 lists the elemental ratios of major elements both for the submicron and the common modes of particles during conditions of heavy loaded atmosphere. We note a similar composition of dust present in both modes, implying that these particles have a common origin. This similar composition strongly suggests that a sandblasting process, which separates the aggregates and/or comminutes the fragile clayey platelets, is the mechanism mainly responsible for the input of submicron size soilderived particles into the atmosphere.

TABLE 1. Elemental Ratios in Both Modes of a Cascade Impactor Sample Collected at El Abiod During a Dust Storm Episode

\begin{tabular}{ccc}
\hline $\begin{array}{c}\text { Sample } \\
\text { EAB86-IV }\end{array}$ & $\begin{array}{l}\text { Submicron Mode } \\
(0.1-1 \mu \mathrm{m})\end{array}$ & $\begin{array}{l}\text { Common Mode } \\
(1-20 \mu \mathrm{m})\end{array}$ \\
\hline $\mathrm{Si} / \mathrm{Al}$ & 1.85 & 2.12 \\
$\mathrm{Fe} / \mathrm{Al}$ & 0.45 & 0.48 \\
$\mathrm{~K} / \mathrm{Al}$ & 0.17 & 0.19 \\
$\mathrm{Ca} / \mathrm{Al}$ & 1.09 & 0.88 \\
$\mathrm{Ti} / \mathrm{Al}$ & 0.055 & 0.058 \\
\hline
\end{tabular}

Previous work supported this idea. In spite of the presence of more than $13 \%$ by mass of particles with diameter $<2 \mu \mathrm{m}$ in the soil of an eroding field of Nebraska, Gillette et al. [1972] estimated that less than $0.8 \%$ of these submicron size soil particles were available as individual particles to become airborne during soil erosion by wind. The other fraction of submicron particles formed aggregations of clay particles, mainly adhering to the surface of large grains. Indeed, these authors presented photomicrographs of thin sections of a soil creep sample which showed a coating of submicron clay platelets on silt and sand particles. Gillette et al. noted that considerable forces were required to dislodge and disaggregate these submicron particles. They concluded that such forces were probably not available for most cases in the abrasion of soil during wind erosion and this could support the lack of submicron particles in the size distributions of aerosol derived from soil.

In summary, when the wind velocity is over the threshold for erosion, the submicron particles presumably enter the atmosphere as aggregated particles, mainly in the form of submicron clay platelet coatings on large particles. Our study suggests that a higher momentum transported to the ground by the wind is therefore necessary to disintegrate and/or comminute the aggregated submicron size soil-derived particles by a sandblasting process. From these results, one might speculate that the collision momentum is then sufficient to break the interparticle bond strengths and remove clay coatings from the surfaces of large particles. The exact nature of the interparticle tensile forces being still in doubt, experiments remain to be performed to determine the amount of energy and number of collisions per unit time necessary to remove coatings. 
Concerning Table 1, a small discrepancy appears for $\mathrm{Si} / \mathrm{Al}$ and $\mathrm{Ca} / \mathrm{Al}$ ratios. On one hand, this confirms the deficiency of quartz particles observed on the backup filter of the impactor in the submicron size mode. On the other hand, it is possible that another process involving $\mathrm{Ca}$ carbonate particles could be superimposed on the sandblasting process to explain the entire submicron component of $\mathrm{Ca}$ particles.

\section{Behavior of the Submicron Particles}

These results remain in accord with previous investigations, particularly with respect to the size distribution measurements by $d$ 'Almeida and Schütz [1983]. Indeed, these authors showed that the stable mode, including particles between 1 and $10 \mu \mathrm{m}$ diameter, was observed for dusty or normal atmospheric conditions, whatever the concentration levels. From their measurements, they concluded that this mode reflects a well-mixed long-range transport fraction of mineral dust particles over the desert. Concerning the concentration of particles $<1 \mu \mathrm{m}$ or $>10 \mu \mathrm{m}$, however, they found a considerable variability which was attributed to the short atmospheric residence times of aerosol particles within these size ranges. Because this variability in the distribution pattern was more pronounced in the range of particle diameter $>10 \mu \mathrm{m}$, these workers did a detailed examination of this upper mode and concluded that these large particles were rapidly removed from the atmosphere, due to their relatively large sedimentation velocities.

Since our study was restricted to the particle size range $0.1-20 \mu \mathrm{m}$, the purpose of this discussion is to supplement the study of d'Almeida and Schütz in the size range of particles smaller than $1 \mu \mathrm{m}$ in diameter. The second mode of finer particles, which clearly appears on Figure 4 during weather conditions involving soil-eroding wind, is centered on $0.3 \mu \mathrm{m}$. Around this particle size, a minimum deposition velocity, coinciding with a maximum of the residence time, is observed [Sehmel, 1980]. Hence, one cannot attribute the main variability in the amplitude of this fine particle mode to removal of aerosols from the atmosphere in the vicinity of the dust source. In a dust transport model for the Sahara, Schütz et al. [1981] show that particles in the size range considered are essentially not removed from the air column once they are injected into the atmosphere. This observation is confirmed by the results of soil size distributions in the Sahara Desert by d'Almeida and Schütz [1983] which indicate a significant loss of small size particles by depletion due to wind erosion.

Thus, since the submicron particle mode is not affected by removal processes on a regional scale, one can conclude that the measurements of aerosol size distribution presented in Figure 4 can be assumed to be representative of a production phase which occurs only during dusty conditions, such as sandstorms. This result supports the hypothesis that this population of very fine particles originates from windblown dust, and is derived from the soils by a sandblasting process.

\section{CONCLUSION}

Mass size distributions of the major elements of the mineral aerosols of northern Sahara have been obtained from measurements carried out with an inertial cascade impactor. A fitting procedure by data inversion, which takes into consideration the main mechanisms of nonideal behavior such as particle bounce-off, wall losses and cross sensitivity which affect the accuracy of impactor measurements on aerosol size distribution, has been applied to these data. This procedure yields accurate size distributions of Saharan aerosols in the range 0.1-20 $\mu \mathrm{m}$ for different conditions of soil mobilization.

Up to now, the volume or mass distribution of the mineral aerosol close to the source regions showed a bimodal structure with a mode characteristic of loose soil aggregates around $60 \mu \mathrm{m}$ and another between 2 and 20 $\mu \mathrm{m}$ resulting in the disaggregation of particles larger than $20 \mu \mathrm{m}$ by a process of sandblasting during erosion conditions. This finer particle mode constitutes the wellmixed long-range transport fraction of mineral dust particles in the desert.

In our measurements, the larger particle mode cannot be observed because these particles are too large to be aspirated by the impactor. However, the finer particle mode clearly appears around $3 \mu \mathrm{m}$, whatever the atmospheric conditions. Moreover, a submicron size particle mode is readily apparent when the wind speed increases above the threshold value for erosion. This mode, which undoubtedly cannot be attributed to anthropogenic secondary aerosol, is rather constituted of submicron windblown dusts. The SEM photographs indicate that the entire granulometric spectrum of the sampled aerosol between 0.1 and $20 \mu \mathrm{m}$ mainly consists of clay easily disaggregated by sandblasting. The common origin of submicron particles and those between 1 and $20 \mu \mathrm{m}$ has been established by showing the similar composition of dusts in both modes. Moreover, a deficiency in quartz coupled with an enrichment in $\mathrm{Ca}$ particles has been observed in the finer population.

These results suggest that the presence of submicron mineral particles during dusty and sandstorm conditions is due to sandblasting processes. When the wind speed exceeds the threshold velocity, more large aggregated particles are injected but, at the same time, the proportion of finer particles also increases. This is probably due to the wind energy which allows an efficient sandblasting process disaggregating the larger particles into smaller ones.

This large relative concentration of submicron particles obviously has important consequences for the optical, chemical and physical properties of the Saharan aerosols.

Acknowledgments. The authors are grateful to J. M. Ajot in the confrèrerie of El Abiod Sidi Cheikh (Algeria) and to Y. Callot of University of Oran (Algeria) for their kind assistance. We also would like to mention the friendly cooperation of $P$. Blanc for SEM and EDXA examinations and B. Chatenet for her technical support, especially for illustration. We are particularly grateful to W. F. Fitgerald and F. Dulac for reviewing our manuscript. This work was supported by the Centre National de la Recherche Scientifique (France). 


\section{REFERENCES}

Bergametti, G., R. Vie Le Sage, B. Grubis, B. Dulieu, and C. Elichegaray, Relation between particulate concentration in the atmosphere and aerosol collection efficiency, Environ. Tech. Lett., 3, 297-304, 1982.

Blifford, I. M., and D. A. Gillette, Applications of the lognormal frequency distribution to the chemical composition and size distribution of naturally occurring atmospheric aerosols, Water Air Soil Pollut., 1, 106-114, 1971.

Carlson, T. N., and S. G. Benjamin, Radiative heating rates for Saharan dust, J. Atmos. Sci., 37, 193-213, 1980.

Carlson, T. N., and R. S. Caverly, Radiative characteristics of Saharan dust at solar wave lenghts, J. Geophys. Res., 82, 3141-3152, 1977.

Chepil, W. S., Sedimentary characteristics of dust storms, III, Composition of suspended dust, Am. J. Sci., 255, 206-213, 1957.

Chepil, W. S., and N. P. Woodruff, Sedimentary characteristics of dust storms, II, Visibility and dust concentration, Am. J. Sci., 255, 104-114, 1957.

d'Almeida, G. A., On the variability of desert aerosol radiative characteristics, J. Geophys. Res., 92, 3017-3026, 1987.

d'Almeida, G. A., and L. Schütz, Number, mass and volume distributions of mineral aerosols and soils of the Sahara, $J$. Clim. Appl. Meteorol., 22, 233-243, 1983.

Davies, C. N., Size distribution of atmospheric particles, $J$. Aerosol Sci., 5, 293-300, 1974.

Dubief, J., Le vent et le déplacement du sable au Sahara, Trav. Inst. Rech. Sahariennes, 8, 123-164, 1952.

Fouquart, Y, B. Bonnel, M. Chaoui Roquai, and R. Santer, Observations of Saharan aerosols: Results of ECLATS field experiment, I, Optical thicknesses and aerosol size distributions, J. Clim. Appl. Meteorol., 26, 28-37, 1987.

Gillette, D. A., On the production of soil wind erosion aerosols having the potential for long-range transport, J. Rech. Atmos., 8, 735-744, 1974.

Gillette, D. A., and W. M. Porch, The role of fluctuations of vertical and horizontal wind and particle concentration in the deposition of dust suspended by wind, J. Geophys. Res., 83, 409-414, 1978.

Gillette, D. A., and T. R. Walker, Characteristics of airborne particles produced by wind erosion of sandy soil, high plains of West Texas, Soil Sci., 123, 97-110, 1977.

Gillette, D. A., I. H. Blifford, Jr., and C. R. Fenster, Measurements of aerosol size distributions and vertical fluxes of aerosols on land subject to wind erosion, J. Appl. Meteorol., 11, 977-987, 1972.

Gillette, D. A., J. Adams, A. Endo, D. Smith, and R. Kihl, Threshold velocities for input of soil particles into the air by desert soils, J. Geophys. Res., 85, 5621-5630, 1980.

Gillette, D. A., J. Adams, D. Muhs, and R. Kihl, Threshold friction velocities and rupture moduli for crusted desert soils for the input of soil particles into the air, J. Geophys. Res., 87, 9003-9015, 1982.

Gillette, D. A., R. N. Clayton, T. K. Mayeda, M. L. Jackson, and K. Sridhar, Tropospheric aerosols from some major dust storms of the Southwestern United States, J. Appl. Meteorol., $17,832-845,1978$.

Gomes, L., G. Bergametti, F. Dulac, and U. Ezat, Assessing the actual size distribution of atmospheric aerosols collected with a cascade impactor, J. Aerosol Sci., 21, 47-59, 1990.
Helgren, D. M., and J. M. Prospero, Wind velocities associated with dust deflation events in the Westem Sahara, J. Clim. Appl. Meteorol., 26, 1147-1151, 1987.

Jaenicke, R., Aerosol physics and chemistry, in LandoltBörnstein, Numerical Data and Functional Relationships in Science and Technology, edited by G. Fisher, new series, vol.4, pp. 391-457, Wiley \& Sons, New York, 1985.

Jaenicke, R., and C. N. Davies, The mathematical expression of the size distribution of atmospheric particles, J. Aerosol Sci., 7, 255-260, 1976.

Junge, C., The importance of mineral dust as an atmospheric constituent, in Saharan Dust, edited by C. Morales, pp. 49-60, John Wiley, New York, 1979.

Kim, Y. J., H. Sievering, and J. F. Boatman, Airborne measurement of atmospheric aerosol particles in the lower troposphere over the Central United States, J. Geophys. Res., 93, 12631-12644, 1988.

Kondratyev, K. Ya., O. B. Vassilyev, V.S. Grischechkin, and L. S. Ivlev, Spectral radiative flux divergence and its variability in the troposphere in the 0.4-2.4 $\mu \mathrm{m}$ region, Appl. Opt., 13, 478486, 1974.

Losno, R., G. Bergametti, and G. Mouvier, Determination of optimal conditions for atmospheric aerosol analysis by $\mathrm{X}$-ray fluorescence, Environ. Tech. Lett., 8, 77-87, 1987.

Patterson, E. M., and D. A. Gillette, Commonalities in measured size distributions for aerosols having a soil-derived component, J. Geophys. Res., 82, 2074-2082, 1977.

Patterson, E. M., D. A. Gillette, and G. W. Grams, The relation between the visibility and the size number distribution of airbome soil particles, J. Appl. Meteorol., 15, 470-478, 1976.

Puttock, J. S., Data inversion for cascade impactors : Fitting sums of log-normal distributions, Atmos. Environ., 15, 1709-1716, 1981.

Pye, K., Eolian Dust and Dust Deposits, 333 pp., Academic, San Diego, Calif., 1987.

Schitz, L., Long-range transport of desert dust with special emphasis on the Sahara, Ann. N. Y. Acad. Sci., 338, 515-532, 1980.

Schútz, L., and R. Jaenicke, Particle number and mass distributions above $10^{-4} \mathrm{~cm}$ radius in sand and aerosol of the Sahara Desert, J. Appl. Meteorol., 13, 863-870, 1974.

Schütz, L., R. Jaenicke, and H. Pietreck, Saharan dust transport over the North Atlantic Ocean, in Desert Dust : Origin, Characteristics, and Effects on Man, edited by T. L. Pewe, Spec. Pap. 186, pp. 87-100, Geol. Soc. Am., Boulder, Colo., 1981.

Sehmel, G. A., Particle and gas dry deposition : A review, Aimos. Environ., 14, 983-1011, 1980.

Westphal, D. L., O. B. Toon, and T. N. Carlson, A twodimensional numerical investigation of the dynamics microphysics of Saharan dust storms, J. Geophys. Res., 92, 3027-3049, 1987.

G. Bergametti and L. Gomes, Laboratoire de Physico-Chimie de 1'Atmosphère, Université Paris 7, 2, place Jussieu, 75251 Paris cedex 05, France.

G. Coude-Gaussen and P. Rognon, Laboratoire des Paléoenvironnements et Paléoclimats en Milieu Aride, Université Pierre et Marie Curie, 4, place Jussieu, 75252 Paris cedex 05, France.

(Received April 14, 1989;

revised January 8, 1990;

accepted January 8, 1990.) 